\title{
Rupture Kinematics of January 24, 2020 Mw 6.7 Doğanyol-Sivrice, Turkey Earthquake on the East Anatolian Fault Zone Imaged by Space Geodesy
}

\author{
Diego Melgar ${ }^{*}$, Athanassios Ganas ${ }^{2}$, Tuncay Taymaz ${ }^{3}$, Sotiris Valkaniotis ${ }^{2,7}$, Brendan W. \\ Crowell $^{4}$, Vasilis Kapetanidis ${ }^{5}$, Varvara Tsironi ${ }^{2,8}$, Seda Yolsal-Çevikbilen ${ }^{3}$, Taylan Öcalan ${ }^{6}$ \\ ${ }^{1}$ Department of Earth Sciences, University of Oregon, USA \\ ${ }^{2}$ Institute of Geodynamics, National Observatory of Athens, Greece \\ ${ }^{3}$ Department of Geophysical Engineering, the Faculty of Mines, Istanbul Technical University, \\ Istanbul, Turkey \\ ${ }^{4}$ Department of Earth and Space Sciences, University of Washington, USA \\ ${ }^{5}$ Faculty of Geology and Geoenvironment, University of Athens, Greece \\ ${ }^{6}$ Department of Geomatic Engineering, Yildiz Technical University, Istanbul, Turkey \\ ${ }^{7}$ Koronidos Str, 42131 Trikala, Greece \\ ${ }^{8}$ Department of Geology, University of Patras, Patras, Greece \\ *Corresponding author: dmelgarm@uoregon.edu
}

This is a non-peer reviewed pre-print submitted to EarthArXiv. This paper has been submitted to Earth and Planetary Science Letters for review.

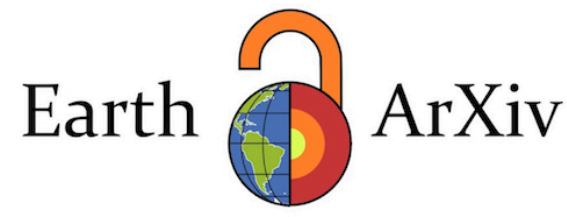




\title{
Rupture Kinematics of January 24, 2020 Mw 6.7 Doğanyol-Sivrice, Turkey Earthquake on the East Anatolian Fault Zone Imaged by Space Geodesy
}

\author{
Diego Melgar ${ }^{1}$, Athanassios Ganas ${ }^{2}$, Tuncay Taymaz ${ }^{3}$, Sotiris Valkaniotis ${ }^{2,7}$, Brendan W. \\ Crowell $^{4}$, Vasilis Kapetanidis ${ }^{5}$, Varvara Tsironi ${ }^{2,8}$, Seda Yolsal-Çevikbilen ${ }^{3}$, Taylan Öcalan ${ }^{6}$ \\ ${ }^{1}$ Department of Earth Sciences, University of Oregon, USA \\ ${ }^{2}$ Institute of Geodynamics, National Observatory of Athens, Greece \\ ${ }^{3}$ Department of Geophysical Engineering, the Faculty of Mines, Istanbul Technical University, \\ Istanbul, Turkey \\ ${ }^{4}$ Department of Earth and Space Sciences, University of Washington, USA \\ ${ }^{5}$ Faculty of Geology and Geoenvironment, University of Athens, Greece \\ ${ }^{6}$ Department of Geomatic Engineering, Yildiz Technical University, Istanbul, Turkey \\ ${ }^{7}$ Koronidos Str, 42131 Trikala, Greece \\ ${ }^{8}$ Department of Geology, University of Patras, Patras, Greece
}

\begin{abstract}
Here we present the results of a kinematic slip model of the $2020 \mathrm{M}_{\mathrm{w}} 6.7$ Doğanyol-Sivrice, Turkey Earthquake, the most important event in the last 50 years on the East Anatolian Fault zone. Our slip model is constrained by two Sentinel-1 interferograms and by 5 three-component high-rate GNSS recordings close to the earthquake source. We find that most of the slip occurs predominantly in three regions, two of them at between 2 and $10 \mathrm{~km}$ depth and a deeper slip region extending down to $20 \mathrm{~km}$ depth. We also relocate the first two weeks of aftershocks and find a distribution of events that agrees with these slip features. The HR-GNSS recordings suggest a strongly unilateral rupture with the effects of a directivity pulse clearly seen in the waveforms and in the measure peak ground velocities. The slip model supports rupture propagation from northeast to southwest at a relatively slow speed of $2.2 \mathrm{~km} / \mathrm{s}$ and a total source duration of $\sim 20 \mathrm{~s}$. In the absence of near-source seismic stations, space geodetic data provide the best constraint on the spatial distribution of slip and on its time evolution.
\end{abstract}

\section{Introduction and tectonic context}

The East Anatolian Fault Zone (EAFZ) forms a 580-km long plate boundary between the Arabian and Anatolian microplates (Allen, 1969; Duman and Emre, 2013), associated with vigorous, shallow seismicity (Taymaz et al., 1991; Tan and Taymaz, 2006; Fielding et al., 2013). Relative plate motion is accommodated primarily by left-lateral strike-slip faulting at slip rates of $10 \pm 1$ $\mathrm{mm} / \mathrm{yr}$ (Taymaz et al., 1991; Reilinger et al., 2006) and has resulted in a series of destructive earthquakes in eastern Turkey as documented by historical records (Ambraseys and Jackson, 1998; Tan and Taymaz, 2006). Recent geological and geomorphic data indicate the East Anatolian Fault (EAF) has displaced the course of Euphrates river by $12 \mathrm{~km}$ since the mid-Quaternary (Trifonov et al., 2018) thus attaining a mean geological slip rate of $12-15 \mathrm{~mm} / \mathrm{yr}$.

In the epicentral region of the $2020 \mathrm{M}_{\mathrm{w}} 6.7$ Doğanyol-Sivrice earthquake (Fig. 1) the EAF cuts through mountainous terrain with elevations ranging between 1-2 km and forms continuous, linear valleys on the landscape. The local geology is part of the Bitlis-Zagros suture zone (Dewey et al., 1973) and it includes Palaeozoic-Mesozoic metamorphic rocks, Mesozoic ophiolitic mélange and 
volcanic rocks (Hempton, 1985) that have been deformed during the Early-Tertiary closure of Neotethys ocean and the south-directed obduction of ophiolites towards the Arabian foreland.

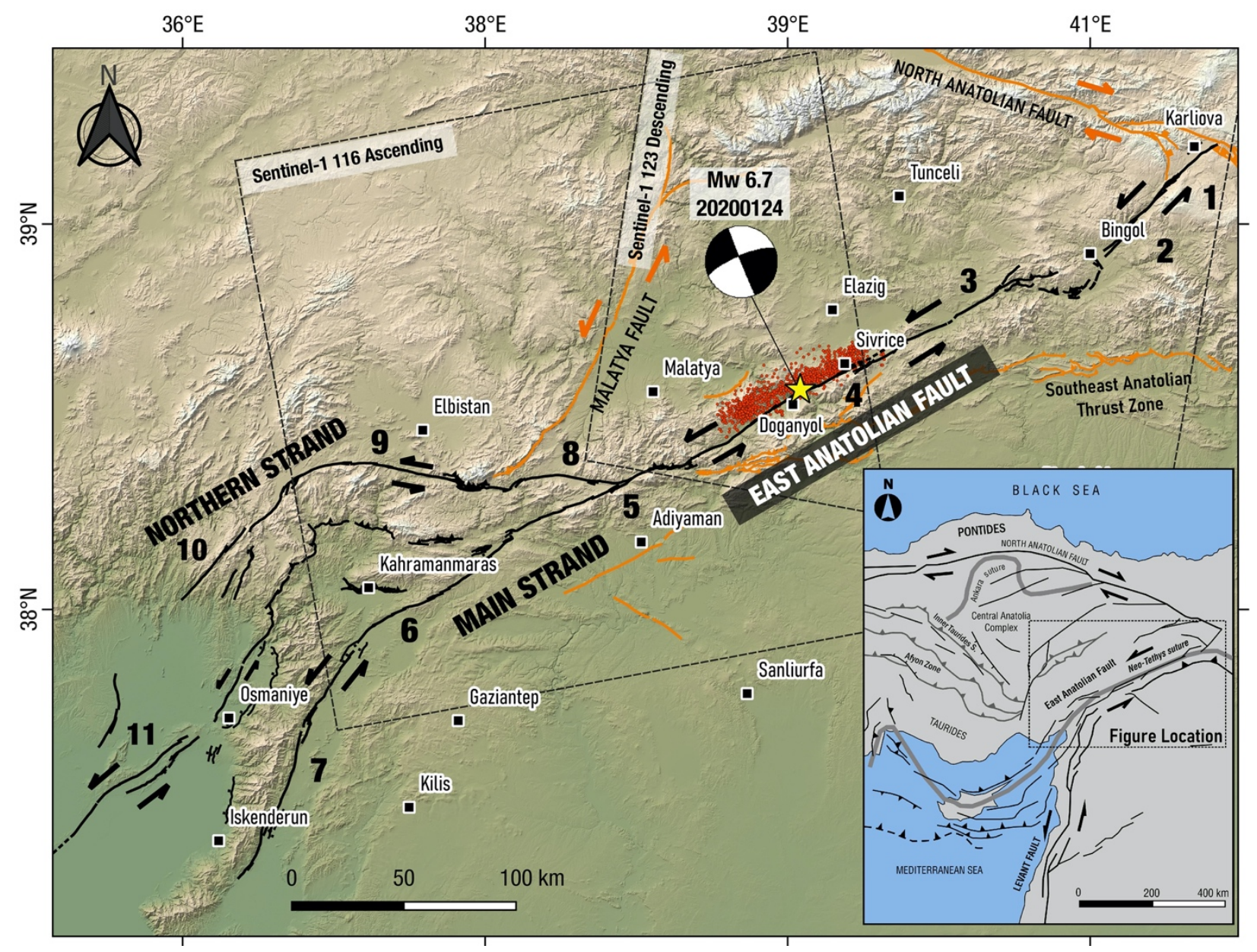

Fig. 1. Relief map of Eastern Anatolia showing the East Anatolian Fault segments (black lines with arrows on either side; numbers 1 to 11 are after Duman and Emre (2013) and refer to 1: Karlıova segment; 2: Illca segment; 3: Gökdere restraining segment; 4: Palu segment; 5: Pütürge segment; 6: Ekenek segment; 7: Pazarcık segment; 8: Sürgü fault segment; 9: Çardak fault segment and Göksun releasing stepover; 10: Savrun fault zone, and 11: Karataş releasing bend. Thin black boxes show extent of satellite imagery. Beach ball indicates the focal mechanism of the January 24, 2020 Doğanyol-Sivrice Mw 6.7 earthquake (yellow star). Red dots indicate the relocated epicentres of the aftershock sequence after AFAD catalogue. Inset box at lower right shows the regional tectonic setting modified after Jolivet et al (2013).

A proper understanding of plate kinematics and the associated tectonic motions in the East Anatolian Fault Zone is crucial for detailed analyses of the present-day deformation of the eastern Anatolia and Mediterranean regions. Furthermore, owing to its high seismic risk and significance for Eurasian and Mediterranean tectonics, Anatolia has been the natural laboratory for multidisciplinary observational studies involving source parameters of historical and modern earthquakes that leverage an array of advanced seismological tools, as well as mapping neotectonics and morphological features along with tomographic, geodynamic and geodetic 
modelling (e.g. Ambraseys 1989; Taymaz et al., 1991; Tan and Taymaz 2006; Taymaz et al., 2004 and 2007a, b; Vanacore et al., 2013; Fielding et al., 2013; Duman and Emre, 2013; Fichtner et al., 2013; Kind et al., 2015; Confal et al., 2018). Previous strong events along the EAFZ include the 1964 Malatya $M s$ 5.7, 1971 Bingöl $M s$ 6.9, 1986 Doğanşehir-Malatya Ms 5.9, 2003 Bingöl $M w$ 6.3, 2004 Sivrice $M w$ 5.5, and 2010 Kovancilar-Elazığ $M w 6.1$ earthquakes. Other major earthquakes include the 1975 Lice Ms 6.7 and 1992 Erzincan Mw 6.7 events which were accompanied by many significant aftershocks on the highly stressed segments of nearby North Anatolian Fault Zone (NAFZ; Fig. 1) and Southeast Anatolian Thrust Zone (SATZ; Fig. 1), also known as Bitlis-Zagros Suture Zone, (see Nabelek 1984; Taymaz et al., 1991; Tan and Taymaz 2006). Furthermore, there have been large, historical earthquakes with $M s \geq 6.6$ in or near the EAFZ between 1500 and 1988 covering broad regions of Tarsus, Malatya, Gönek, Palu, Kulp, Amik Gölcük, Aafrine (e.g. Ambraseys 1989; Ambraseys and Jackson, 1998). The occurrence of large, destructive earthquakes along several crustal-scale faults indicates the complexity of ongoing deformation processes inside the collisional zone between Arabia and Eurasia.

In this study, we investigate the slip distribution of the January $24^{\text {th }}, 2020 M w 6.7$ earthquake near the towns of Doğanyol-Malatya and Sivrice-Elazığ (eastern Turkey, Fig. 1). We place particular emphasis on its rupture kinematics from the joint inversion of two interferograms produced from Sentinel-1 Copernicus Synthetic Aperture Radar (SAR) acquisitions (Fig. 2) and high rate (1 sample per second / $1 \mathrm{~Hz}$ ) Global Navigation Satellite System (HR-GNSS) recordings from a regional national geodetic network of Turkey (Fig. 3). In absence of near field strong motion recordings, these space geodetic observations provide the only regional constraints on the slip characteristics of the earthquake and on its time evolution. We analyze the relationship between the crustal deformation pattern of the mainshock, the aftershock patterns on the EAF and how this relates to rupture segmentation and strain release. Furthermore, we will analyze the directivity and strong ground motions derived from the HR-GNSS observations and provide insights to seismic hazard in the East Anatolia and surrounding regions.

\section{Geodetic data and inversion technique}

\section{$\underline{2.1 \text { InSAR }}$}

Synthetic aperture radar (SAR) interferometry can be used to detect changes in the ground surface between two satellite overpasses, by removing the signal from the topography (e.g. Ganas et al., 2018, 2019; Ilieva et al., 2016; Feng et al. 2016). Here, we use differential SAR Interferometry to capture the deformation produced by the Doğanyol-Sivrice earthquake. We constructed co-seismic interferograms by combining topographic information with SAR acquisitions from the Sentinel-1 satellites for both ascending track 116 and descending track 123. The SAR acquisitions were processed in the Geohazards TEP cloud platform, using the open-source SNAP v5.0 ESA software (Veci et al., 2014). For the ascending track, the pre-event acquisition is from January $15^{\text {th }}, 2020$ and the repeat pass is from January $27^{\text {th }}, 2020$. For the descending track, the pre- and post-event acquisitions are from January $16^{\text {th }}, 2020$ and on January $28^{\text {th }}, 2020$ respectively (Fig. 2)

The interferogram was formed by cross-multiplying the master image (the pre-event acquisition image) with the complex conjugate of the slave (the post-event image). The resulting phase represents the difference between the two images. We eliminate, as much as possible, sources of error to be able to isolate the remaining signal that is likely to be related to the ground 
displacement. During the interferogram formation step, we removed the flat-Earth phase and flattened the images and applied topographic phase compensation from the 3-arcsecond Shuttle Radar Topography Mission (SRTM) digital elevation model (Farr et al., 2007). In order to reduce the effects of phase noise, adaptive filtering (Goldstein and Werner, 1998) was applied with a small window size (10x10 pixels) and with a coherence threshold of 0.3 . Phase unwrapping was carried out using the automatic unwrapping SNAP tool (SNAPHU; Chen and Zebker, 2002; Fig. 2). The mapped LOS displacements reach $45 \mathrm{~cm}$ of relative block motion with a left-lateral sense of slip. Most of the displacement occurs towards the south-west of the epicentre. We also constructed two profiles normal to the strike of the EAFZ to show the tectonic motions with respect to the underlying topography (drawn from ALOS Global DSM $30 \mathrm{~m}$ resolution; Fig. 2 bottom panels). Finally, we down-sample the unwrapped interferogram using the QuadTree algorithm (Lohman and Simmons, 2005), which preserves more data points in areas where the surface displacement is changing quickly and fewer in areas of smoothly varying displacements (Fig. 4a, $4 b)$.
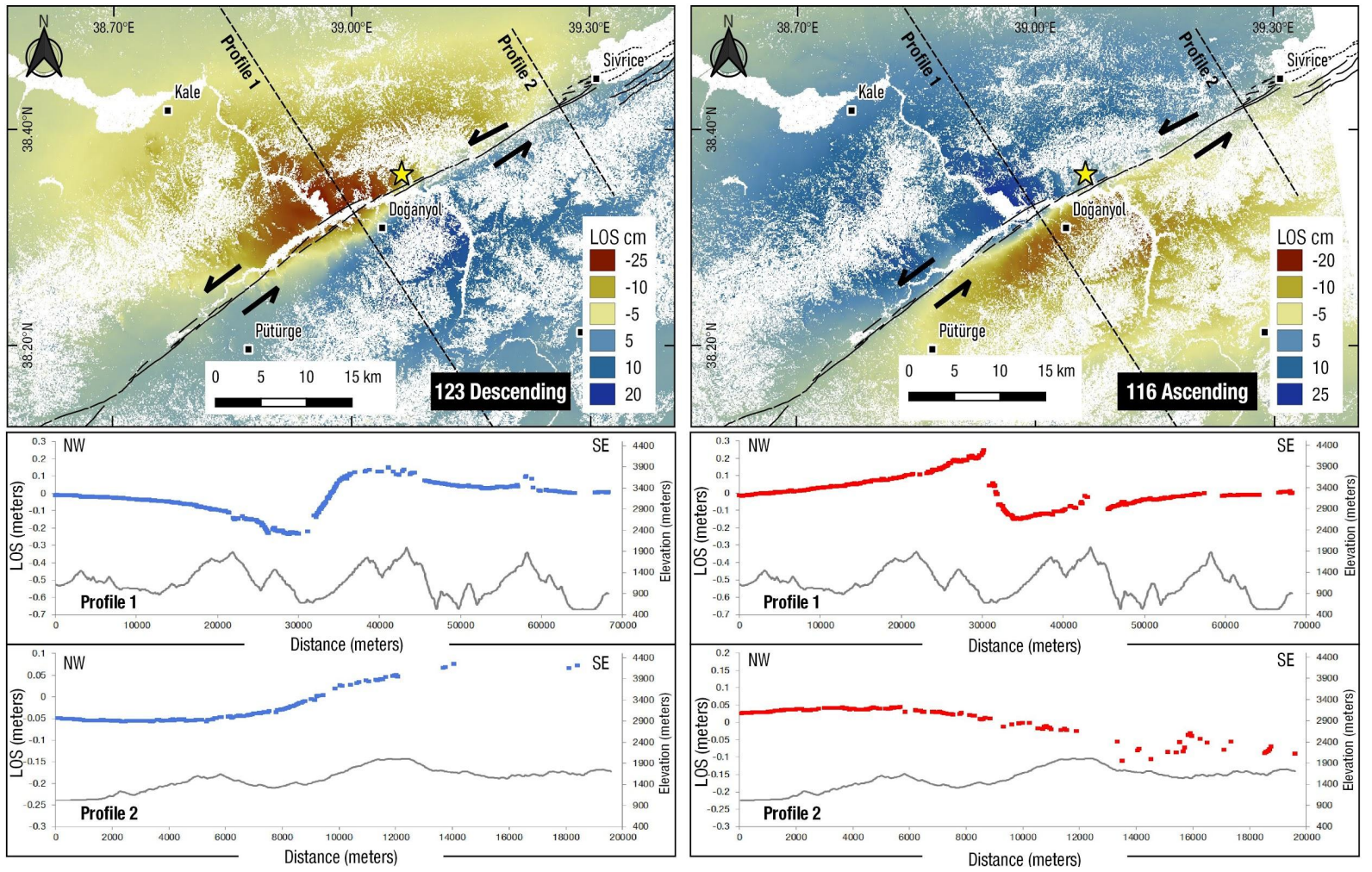

Fig. 2. InSAR Line-of-Sight (LOS) displacement maps (top) and cross-sections in two profiles that are perpendicular to the main fault (bottom). Positive indicates motion towards the satellite. White colour on maps indicates no data and/or water bodies. Left panels show results for the descending track (123), right panels for the ascending track (116), respectively. Cross-sections are oriented normal to the EAFZ. Grey colours show topographic profiles along the same traverses. Black halfarrows indicate sense of left-lateral strike-slip relative motion, as inferred from the LOS maps.

\subsection{High-Rate GNSS}


We processed one hour of data around the earthquake for 9 high-rate GNSS stations in the region, 5 of which (Fig. 3) are within $120 \mathrm{~km}$ of the epicentre and show meaningful displacement signals (Fig. 4). The positions were obtained using the TRACK software, which is part of the standard GAMIT/GLOBK distribution (Herring et al., 2010), using data from station ADN1 as the reference site. This station is chosen as a reference because it is located $360 \mathrm{~km}$ from the epicentre. The reference station undergoes motion at $120 \mathrm{~s}$ after origin time due to the arrival of shear waves and the signal is amplified by source directivity. However, we only utilize data from the first minute of the earthquake for our inversion so none of the motion at the reference station is propagated into other stations. We utilized rapid orbit and clock products from the International GNSS Service (IGS - http://www.igs.org). We make the HR-GNSS waveforms in miniSEED format available in the supplement. The calculated positions are in Earth Centered Earth Fixed (ECEF) geodetic coordinates and are rotated to the more familiar topocentric coordinate system with its components as north, east, and vertical (Fig. 4c).

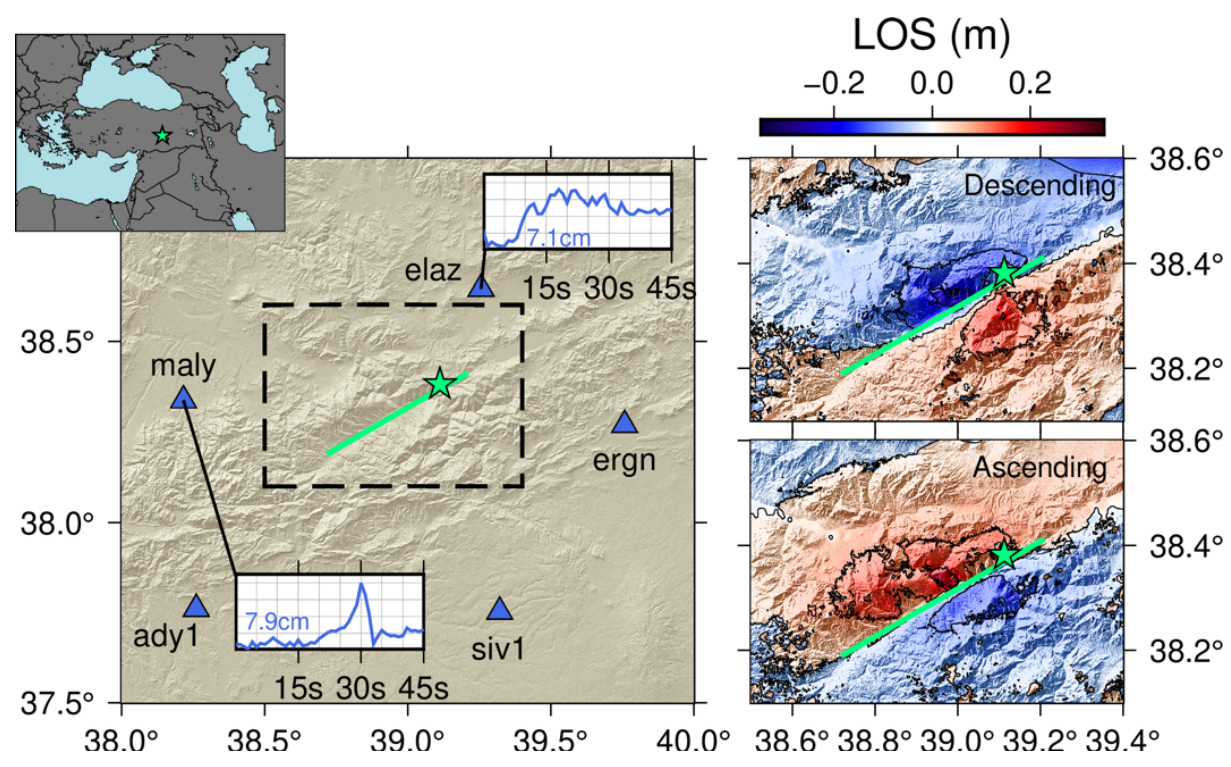

Fig. 3. (Left) Location of the five HR-GNSS sites used in this study. Insets show the total displacement waveform obtained as the epoch by epoch L2 norm of the three-component displacement for two example sites, ELAZ and MALY located on either side of the mainshock's epicentre. The green star is the epicentre and the thick green line denotes the surface trace of the fault geometry used for inversion. (Right) InSAR displacement field indicating most of surface deformation occurring to the $S W$ of the epicentre.

\section{$\underline{\text { 2.3 Joint kinematic inversion }}$}

We jointly invert the two InSAR scenes, as well as the three components of motion for the 5 closest HR-GNSS sites. We assume an $80^{\circ}$ northwest-dipping fault with a strike of $245^{\circ}$, consistent with global moment tensor solutions, and extend the fault up-dip from the hypocentre in order to intersect the surface at the mapped surface trace of the EAF Zone. This coincides well with the polarity change in displacement on both InSAR scenes. We discretize the fault into 34 along-strike and 13 down-dip 1.5 by $1.5 \mathrm{~km}$ subfaults. We use the hypocentre $\left(39.1126^{\circ} \mathrm{E}, 38.3821^{\circ} \mathrm{N}, 8.9 \mathrm{~km}\right)$ 
and origin time (17:55:16 UTC) information of the mainshock based on solution from the Kandilli Observatory and Earthquake Research Institute (KOERI) for the earthquake.

LOS residual $(\mathrm{m})$

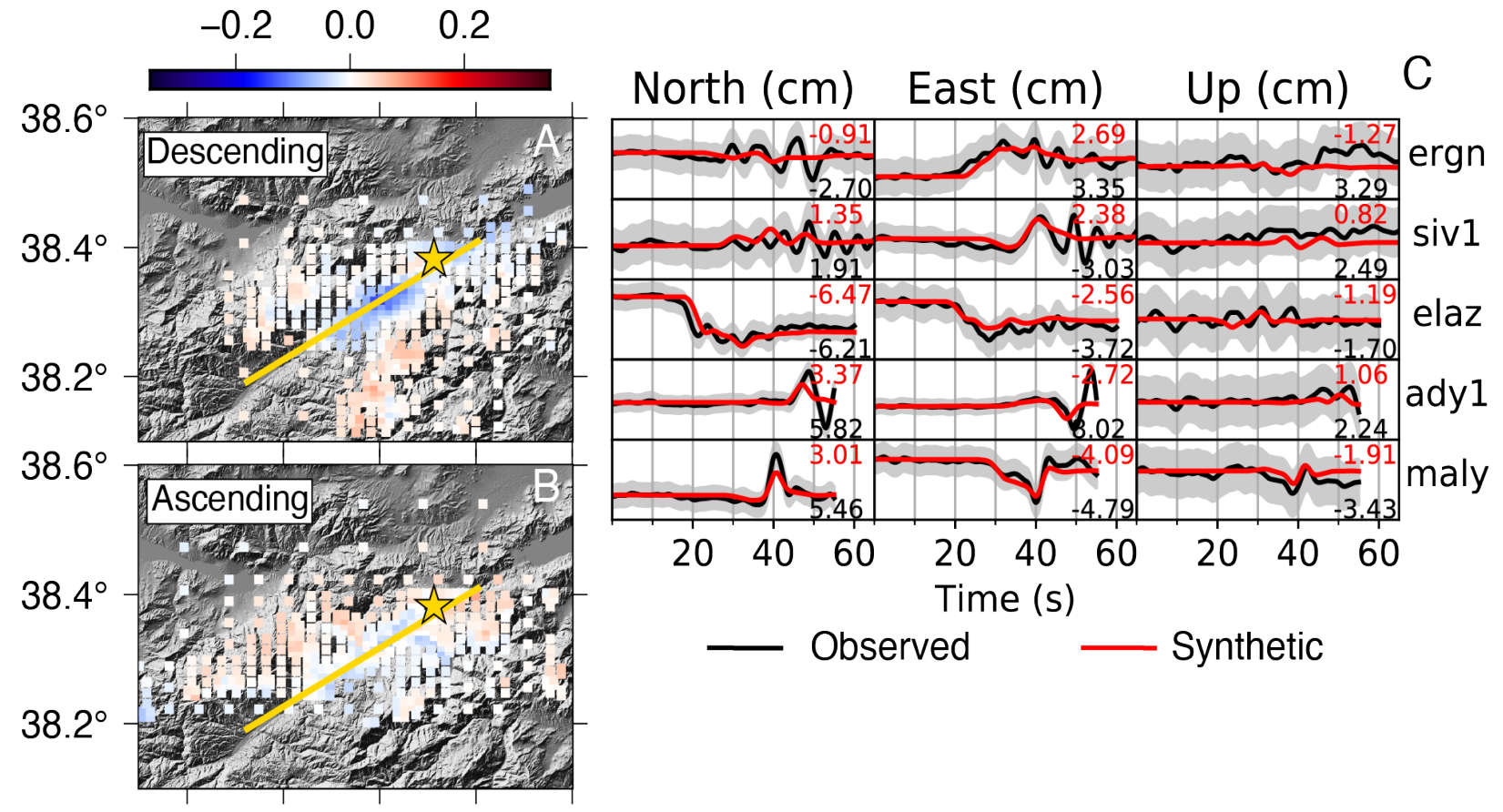

$38.6^{\circ} 38.8^{\circ} 39.0^{\circ} 39.2^{\circ} 39.4^{\circ}$

Fig. 4. (A) Residual fits of the preferred slip model to the Quad Tree down-sampled descending track. (B) Residual fits to the ascending track. (C) Fits to the HR-GNSS. Black and red correspond to the observed and modelled waveforms, respectively. The numbers above each waveform indicate the peak amplitude. The grey-shaded regions are the measurement uncertainty.

We generate elastostatic and elastodynamic Green's functions for the InSAR and HR-GNSS using the frequency-wavenumber integration approach of Zhu and Rivera (2002). For Earth structure we employ a 1D layered velocity model extracted from the LITHO1.0 global crustal model at the location of the hypocenter (Pasyanos et al., 2014). The local slip at each subfault is parameterized with five $50 \%$ overlapping triangle slip-rate functions, each with a duration (rise-time) of $2 \mathrm{~s}$. The rupture speed is determined by trial and error. We performed inversions at 10 different rupture speeds between 1.2 and $2.8 \mathrm{~km} / \mathrm{s}$ (Fig. 5) and retain the one with the best fit to the data. For this earthquake this is $2.2 \mathrm{~km} / \mathrm{s}$.

We employ the MudPy open source Python code for inversion (Melgar and Bock, 2015), which uses a non-negative least squares solver. We limit the slip to a $90^{\circ}$ window in rake around a value of $270^{\circ}$ (left-lateral strike-slip). Kinematic inversion is a rank-deficient problem and hence we regularize it by enforcing minimum norm (Tikhonov) smoothing. The optimum smoothing parameter is determined through the L-curve criterion analysis (Melgar et al., 2013). For inversion with multiple data sets, defining the relative weights or the importance between each one is a somewhat ambiguous process. We follow the procedure outlined by Melgar et al. (2016) and assign equal importance to both the InSAR and HR-GNSS by normalizing each individual data set 
by its norm. This ensures that neither of the two is preferentially fit in the inversion. We then define a covariance matrix based on the far-field noise observed in each interferogram, as well as the preevent noise in each HR-GNSS recording. This represents an uncertainty on each measurement. An example of this can be seen in the grey-shaded regions surrounding the HR-GNSS waveforms in Fig. 4c.

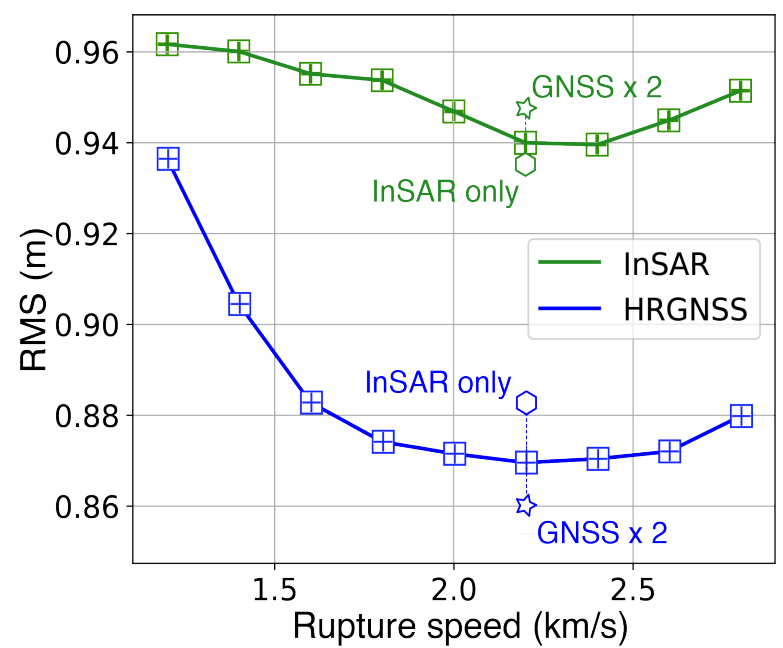

Fig. 5. RMS misfit to each data set as a function of rupture speed. Note that while the InSAR is not directly sensitive to rupture kinematics, its misfit will be affected by the choice of rupture speed in the joint inversion. We choose $2.2 \mathrm{~km} / \mathrm{s}$ as the best fitting rupture speed. RMS measurements are also presented for an inversion where the HR-GNSS was artificially upweighted ("GNSS $x$ 2"; star), as well as for another with only the InSAR data (InSAR only; hexagon).

\section{Aftershock relocation}

Initial catalogue and phase-arrival data were acquired from the bulletin of the Disaster and Emergency Management Presidency of Turkey (AFAD) for over 2400 earthquakes in the region between $37.971^{\circ} \mathrm{N}-39.392^{\circ} \mathrm{N}$ and $38.427^{\circ} \mathrm{E}-39.729^{\circ} \mathrm{E}$ for the period between January $24^{\text {th }}$ and February $11^{\text {th }}, 2020$. From the automatic locations we noticed that many of the hypocenters were located at a fixed depth of $7 \mathrm{~km}$, therefore, their 3D spatial distribution cannot be properly examined using this preliminary catalogue alone. To improve the solutions, we proceeded with the construction of a velocity model for this sequence. We employed a starting velocity model that is originally based on the surface wave inversion by Delph et al. (2015) for the S-wave velocity variation down to a depth of $40 \mathrm{~km}$ (see Supplementary Table 1). To acquire an initial re-located catalogue, we use the HypoInverse code (Klein, 2002) with this starting model. We then proceeded to investigate the model space and potential perturbations to the local velocity structure by performing a series of inversions using the VELEST algorithm (Kissling et al., 1994). This produces an optimal P-wave velocity model, which relies on only P-wave arrival-times and the initial hypocentres as determined by the starting model. A subset of hypocentre data with the 680 best-located events (RMS error $<0.5 \mathrm{~s}$, horizontal and vertical location errors $<3 \mathrm{~km}$, with at least 6 P-wave arrivals and azimuthal gap $<180^{\circ}$ ) was selected. Preliminary runs performed with VELEST using the starting model were followed by a further removal of stations with very few observations and events that yielded RMS larger than twice the average RMS of the subset at the final iteration. Then, with the remaining dataset of 390 events, a series of 100 inversions were 
performed with VELEST. Each inversion began with a velocity profile based on the starting model but with different layer thicknesses. The final model that yielded the smallest RMS value is considered to be the optimal one (Supplementary Table 1). The events were then re-located by using the HypoInverse code and the current optimal velocity model.

To further improve the spatial distribution of hypocenters, relocation was performed using the double-difference method (HypoDD; Waldhauser, 2001). This algorithm reduces relative location errors by minimizing the double-difference between the observed and calculated travel-times for pairs of neighbouring events. When the distance between two hypocenters is much smaller than the length of their ray-paths to a station, differences in their travel-times can be attributed to their inter-event distance. At this stage, catalogue-based travel-time data were used only, as waveform data from local stations were unavailable for this sequence. The catalogue-based differential traveltime data were constructed with links between hypocenters with inter-event distance of up to 10 $\mathrm{km}$ and with a minimum of 8 links to define up to 4 neighbours. The relocation was performed in a single set of 15 iterations, with dynamic down-weighting of observations with large residuals. Using HypoDD, a total of 1433 events in AFAD catalogue were successfully relocated (see Supplementary Fig. 2 for a comparison to catalogue locations).

\section{Results}

The HR-GNSS waveforms strongly suggest a unilateral north-east to south-west rupture. Stations MALY and ADY1 clearly show a directivity pulse in the displacement field (Figs 3 and 4c; Sommerville, 2003). Meanwhile stations ELAZ and ERGN, to the east of the rupture, show a simpler co-seismic step with no pulse-like character. This is confirmed by the results of slip inversions (Fig. 6) and by its time evolution (Fig. 7). While there are approximately $8 \mathrm{~km}$ of fault that ruptured to the northeast of the hypocenter, most of the slip $(\sim 30 \mathrm{~km})$ occurs to the southwest. The model produces $\sim 3.5 \mathrm{~m}$ of peak slip, which occurs $10 \mathrm{~km}$ away from the hypocenter and has a source duration of 18-20 s with a total magnitude of $M w 6.75$. Most of the slip occurs above 10 $\mathrm{km}$ depth within two main asperities (S1 and S2 on Fig. 6), a smaller one to the northeast and a much larger one to the southwest. We also see a broad diffuse region of slip immediately below the hypocentre (S3) extending down to $20 \mathrm{~km}$ depth. Interestingly, there is a roughly circular slip void with a diameter of about $10 \mathrm{~km}$, immediately to the west and down-dip of the hypocentre.

The fits to the data are overall good (Fig. 4), however we note that the displacement pulse at the western sites ADY1 and MALY is underestimated by the model. In an attempt to improve on this, we also ran a slip inversion where we upweighted the HR-GNSS data by a factor of 2. Indeed, as can be seen in Fig. 5, the HR-GNSS RMS misfit decreases, however this is at the expense of increasing the misfit to the InSAR data. The resulting slip model from these higher HR-GNSS weights has the same characteristics but with much higher slip (Fig. 6) on asperities S2 and S3 that reach almost the same peak value $(\sim 3 \mathrm{~m})$ as the main asperity $\mathrm{S} 1$. For completeness, we also ran a slip inversion with zero weight on the HR-GNSS, essentially allowing for only the InSAR data modelling. This third inversion is, strictly speaking, a static inversion, but we can use the preferred rupture speed of $2.2 \mathrm{~km} / \mathrm{s}$ to evaluate how well this model fits the HR-GNSS. We find that with this model the RMS misfit to the InSAR improves, at the expense of the HR-GNSS (Fig. 5). The shallow asperities S1 and S2 remain fairly similar to those in the preferred model, but the deep asperity S3 is much diminished in this model. 


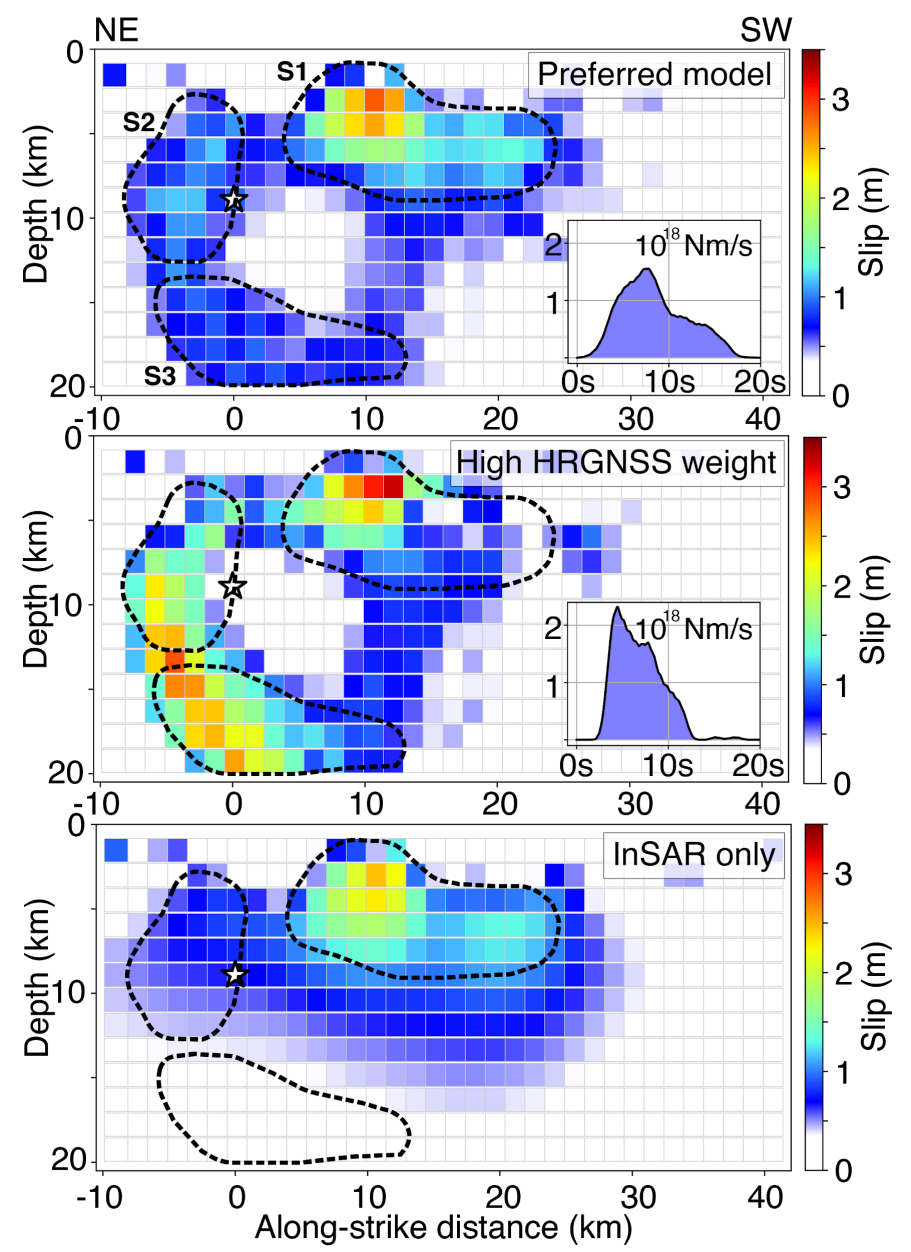

Fig. 6. Slip inversion results. The preferred model (top panel) is outcome from the joint inversion of InSAR and HR-GNSS with equal weights to each data set. In the high HR-GNSS weight model (middle panel) we have doubled the importance of the HR-GNSS. The InSAR only model (bottom panel) does not include the HR-GNSS waveforms. The dashed lines denote the main features observed in the preferred inversion, labelled $S 1, S 2$, and $S 3$, and are meant as a reference to compare against other models.

The $\mathrm{N} 65^{\circ} \mathrm{E}$ oriented distribution of the relocated aftershock sequence is $68-70 \mathrm{~km}$ long (Fig. 8; see Supplementary Fig. 3 for a cross-section view). The spatial distribution of the relocated hypocentres is sub-vertical, but with a definite tendency of dip towards NNW and with aftershock activity sharply decreasing three-days after the mainshock (see supplementary Fig. 4). Two methods were applied to determine the geometry of the aftershock distribution, first a least-squares fit of a 2D plane and second the three-point method of Fehler et al. (1987) (Supplementary Fig. 1). In the latter method, for each triangle formed by every three hypocentres, its plane geometry is measured in terms of its strike (or dip-direction) and its dip angle. This process is repeated for all combinations of relocated hypocentres by three. Then, the distribution of these results is examined and the strike/dip combination with the highest density of measurements is selected as the optimal plane. The solutions from both methods indicate a strike of $245^{\circ}-246^{\circ}$, while the dip is $72^{\circ}$ with the least-squares method and $69^{\circ}$ with the three-point method. These results are nearly identical to the strike of the main fault $\left(244^{\circ}-246^{\circ}\right)$ as determined by the moment tensor solutions for the 
mainshock derived by several institutes (e.g. Harvard's GCMT: strike $=246^{\circ}$, dip $=67^{\circ}$; USGS: strike $=244^{\circ}, \operatorname{dip}=79^{\circ}$ ), corresponding to the East Anatolian Fault. The spatial distribution was divided in four groups, by applying Ward's linkage on the 3D inter-event distances matrix and using an appropriate threshold (Fig. 8). Cluster \#2, at $\sim 5-20 \mathrm{~km} \mathrm{SW}$ of the mainshock, presents lack of activity, compared to the other groups, especially at the shallower depths $(5-10 \mathrm{~km}$; see also Supplementary Figure 3). This void of seismicity roughly matches the high coseismic slip patch S1.

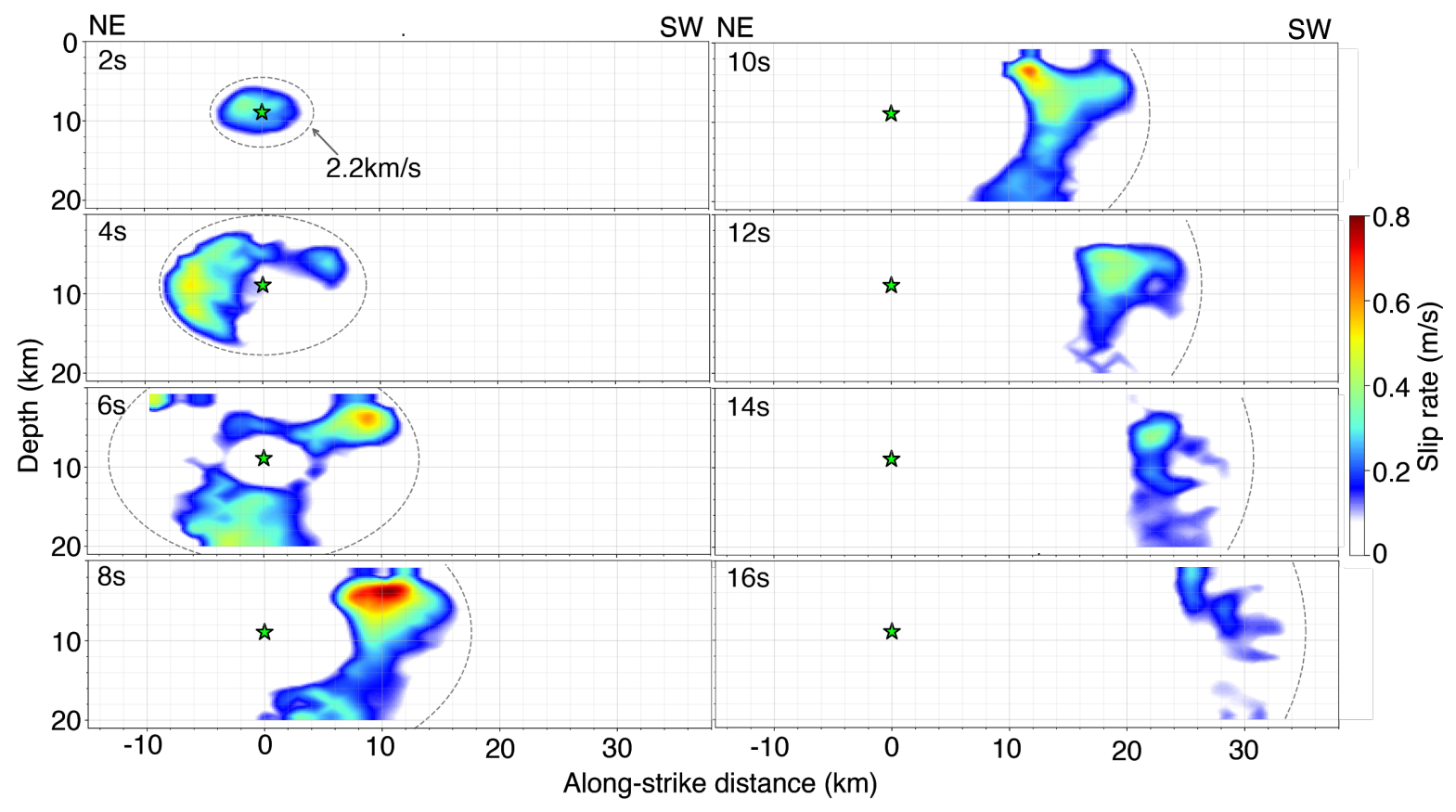

Fig. 7. Snapshots of the rupture evolution for the preferred model. Plotted is the interpolated local slip rate on the fault at $2 s$ intervals. The dashed line is the maximum allowed rupture speed of 2.2 $\mathrm{km} / \mathrm{s}$. An animation of these snapshots can be found in Movie S1.

\section{Discussion}

\subsection{GNSS and ground motion estimates}

The $2020 M w 6.7$ Doğanyol-Sivrice earthquake is the most significant event that has occurred in the EAF in the last 50 years (since the 1971 Bingöl Ms 6.9 earthquake). In the absence of nearsource seismic data, space geodesy provides the only regional constraints on the geographic extent, the details of slip and its time evolution. Indeed, the 1-Hz time series of ground motion, recorded by the near-source sites, already present strong evidence of directivity effects from a predominantly unilateral rupture. We can expand this more by making a single-difference in time between the satellite ranges and phase observables to produce GNSS velocities. This approach was originally demonstrated by Colosimo et al. (2011) and has been successfully used for recording strong ground motions with GNSS. Computing the 3-component peak ground velocity (PGV) at the southwestern sites (ADY1 and MALY) yields PGV estimates of 8.6 and $4.0 \mathrm{~cm} / \mathrm{s}$. According to the ground motion to intensity conversion equations of Worden et al. (2012), this corresponds to modified Mercalli intensity (MMI) values of 5.8 and 4.8. Meanwhile the northwestern sites at 
similar distances (ELAZ and EGRN) have more muted PGV values of 2.4 and $3.0 \mathrm{~cm} / \mathrm{s}$ equivalent to MMI 4.3 and 4.5. Using HR-GNSS to characterize ground motion is not common practice, but has been performed earlier, in particular to study basin resonance effects during the 2015 M7.8 Gorkha, Nepal earthquake (Galetzka et al., 2015). While HR-GNSS samples ground motion at slower rates than inertial sensors, it can still provide important information. One possible pitfall, nevertheless, is the aliasing of strong motions when using $1 \mathrm{~Hz}$ recordings, as previously seen in other single event studies using HR-GNSS-derived velocities (Grapenthin et al., 2017; Shu et al., 2018). However, a systematic comparison between intensities derived from GNSS and strong motion sensors has not been yet carried out and is a topic of future research. Despite this, here we show that useful information about directivity and site effects can be obtained when comparing relative peak ground motions.

In fact, there has been considerable seismic damage observed in existing buildings, as confirmed by official preliminary field reports (e.g. AFAD 2020; MTA 2020). Investigations made in the region reveal that mostly non-engineered 1-2 story rural buildings have experienced heavy structural damages or severe collapses. Low material quality, such as using low strength stones (mostly rubble) and mud mortar, likely led to such collapses. As for the reinforced concrete (RC) framed buildings with 3-8 storeys, major structural problems previously encountered in the past historical earthquakes in Turkey have been observed in this case as well. Whether the pattern of damages is consistent with the directivity effects, as shown here, or other path or site amplification effects are responsible is not yet known.

\subsection{Robustness of the resolved slip patches and source characteristics}

Obtaining low residual fits to the strong pulse of ground motion in the HR-GNSS data from the slip inversion is challenging though (Fig. 5). It is possible to improve these fits by increasing the weights in the inversion assigned to the HR-GNSS. However, doing this comes at the expense of increasing the misfit to the InSAR. Additionally, this increased weighting also increases the overall slip in regions S2 and S3 (Fig. 6). Indeed, an important question is whether this deep slip, particularly in region S3, and the slip void next to it, are reliable features. To explore this, we have carried out two different resolution tests (Fig. 9). The first is a classic checkerboard test with 4.5 by $4.5 \mathrm{~km}$ checkers with $1 \mathrm{~m}$ of slip. We generated synthetic HR-GNSS and InSAR data and contaminated them with noise similar to what is seen in the observations. We then inverted both datasets with the same rupture speed and regularization parameter as in the preferred model in Fig. 6 . The results show that the HR-GNSS has only a slight depth bias, with deeper checkers having slightly more smearing. However, overall, the five three-component stations are sensitive to slip everywhere on the fault. Meanwhile, the InSAR data completely smears out all the slip below $\sim 10$ $\mathrm{km}$, most likely due to the near-vertical geometry of the fault. This is important because the bottom half of slip region S2, and the entirety of slip region S3 are contained within the smeared-out region. We carried out a second jackknife sensitivity test (Kim and Dreger, 2008) where we remove $25 \%$ of the dataset and carry out the inversion. We replace the data and randomly remove another $25 \%$. We perform this procedure about 200 times to obtain estimates of the uncertainty of the slip at each subfault as represented by the width of the $95 \%$ confidence interval in Fig. 9. In addition to this, we present the coefficient of variation, which simply represents the ratio between standard deviation of slip and the mean slip. The coefficient of variation is low in all three slip regions, which suggests that they constitute features which are pervasive and routinely required by the inversion. It is important to note, as well, that the slip void has a somewhat elevated coefficient 
of variation, implying that it need not be a zero slip region, but, instead, it could be simply a region with low slip.
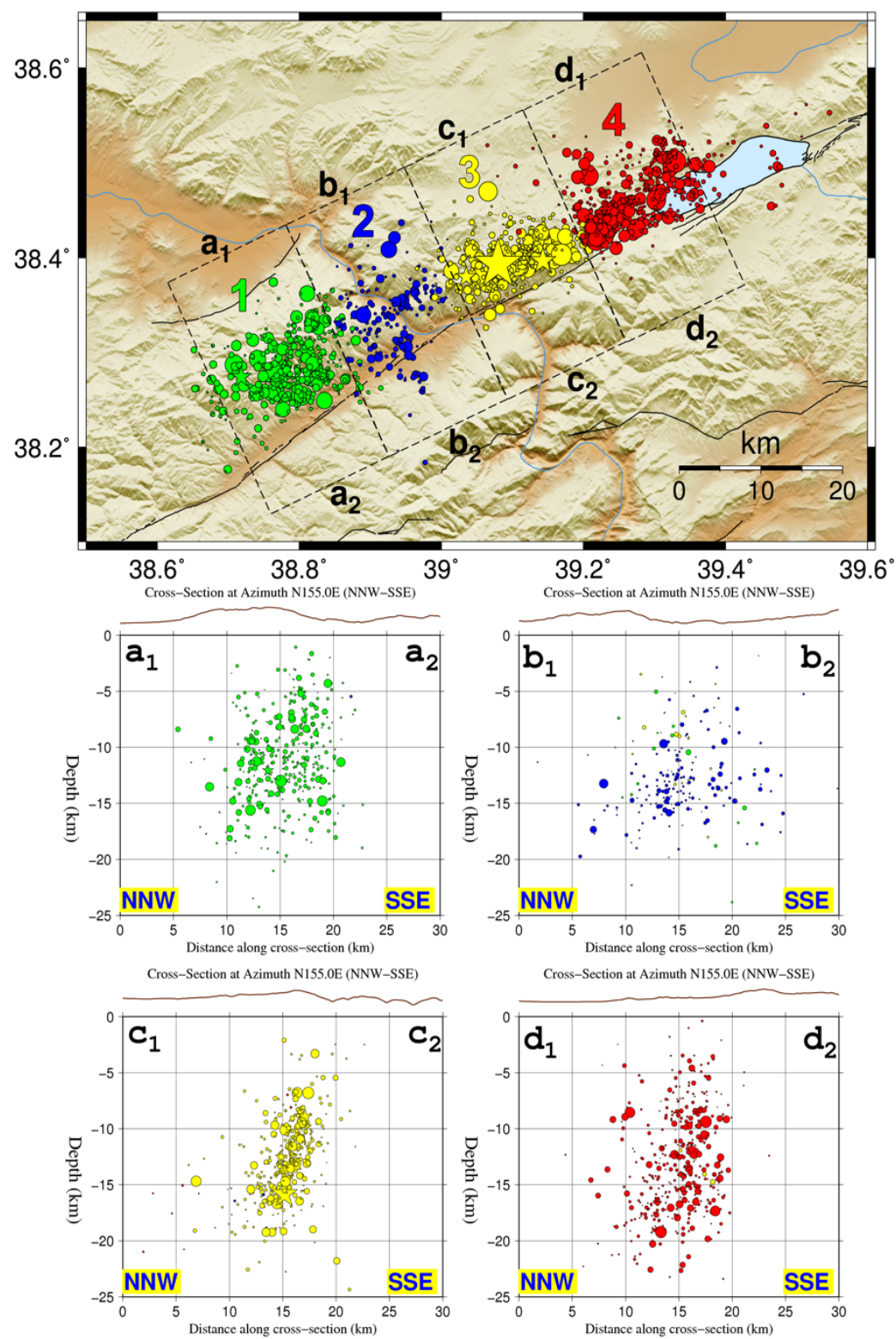

Fig. 8. Aftershocks map after relocation and cluster analysis with HypoDD. Seismicity crosssections (16 km wide) are oriented NW-SE and depict hypocentres at depths 5-20 km. Symbol size is proportional to magnitude while events with $M \geq 4.5$ are depicted by stars. The large yellow star indicates hyponcentre of mainshock. Colours and numbers indicate four distinct spatial groups (see also Supplementary Figs 3 and 4).

Overall, both of these resolution analyses suggest that slip regions S1 and S2 are most likely real features, as is the deeper slip region S3. This implies that the seismogenic portion of the crust spans from the surface of the fault and extends down to the depth of $\sim 20 \mathrm{~km}$. This is consistent with both pre-event seismicity and the aftershocks distribution displayed in Figs 8 and 10. There we have supplemented our relocated aftershock catalogue with pre-event seismicity from the KOERI 
catalogue dating back to 1992 and obtained seismicity within $20 \mathrm{~km}$ of the fault trace. Both clearly show that the seismogenic depth extends to at least $\sim 20 \mathrm{~km}$. After this depth, there is a clear drop in the number of events. Similarly, we see relatively low aftershock productivity within all three slip regions while there is a distinct cluster of aftershocks within the slip void. These features in the pre- and post-event seismicity and the main features of our slip inversion are consistent. Finally, we note that the along-strike distribution of both the pre- and post-event seismic activity show a clear drop in the number of events within the region that slips. This suggests perhaps coupling along this portion of the EAF where the area that ruptured during the Doganyol-Sivrice earthquake was highly, and thus not generating as much microseismicity, in the inter-seismic period.

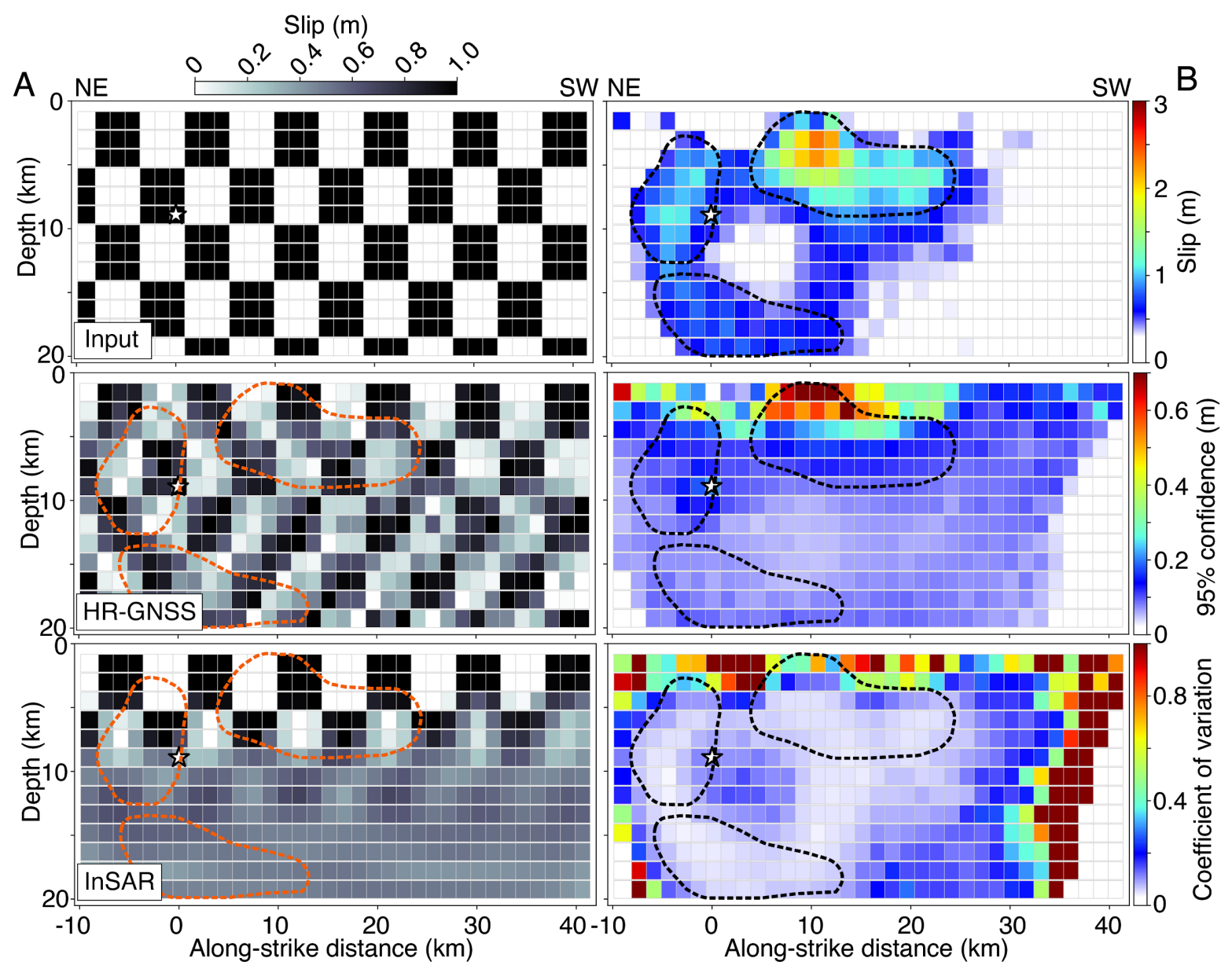

Fig. 9. Resolution analysis of the inversion. (Left) Checkerboard test with input checkerboard model (top) and results after inverting just the HR-GNSS (middle) and just the InSAR data (bottom). (Right) Jackknife sensitivity test with mean model (top), 95\% confidence interval (middle) and coefficient of variation (bottom). The dashed regions on each panel indicate the slip patches S1-S3 from Fig. 6.

The dimensions of the causative fault for the Doğanyol-Sivrice earthquake $(\sim 35 \mathrm{~km} \times 20 \mathrm{~km})$ are consistent with what is seen in scaling laws from worldwide events (e.g. Allen \& Hayes, 2017). The peak slip of $\sim 3.5 \mathrm{~m}$ is somewhat higher than what is predicted by some scaling laws $(\sim 2.5 \mathrm{~m})$, but still within the uncertainty in the scaling laws. We note that the preferred rupture speed $(2.2$ 
$\mathrm{km} / \mathrm{s}$ ) is $60 \%$ of the shear wave speed at the hypocentral depth. This is somewhat slow but still within what has been observed worldwide in other ruptures (e.g. Melgar \& Hayes, 2017). We tested many candidate rupture speeds and it is clear that $2.2 \mathrm{~km} / \mathrm{s}$ is preferred by the data (Fig. 5). However, we note that while the time-varying displacements recorded by HR-GNSS are indeed sensitive to the choice of rupture speed, they are less so than strong motion records integrated to velocity (e.g. Melgar et al., 2016), which are not available for this event. So, there is room for further investigations, such as using back-projection techniques, to confirm this observation.

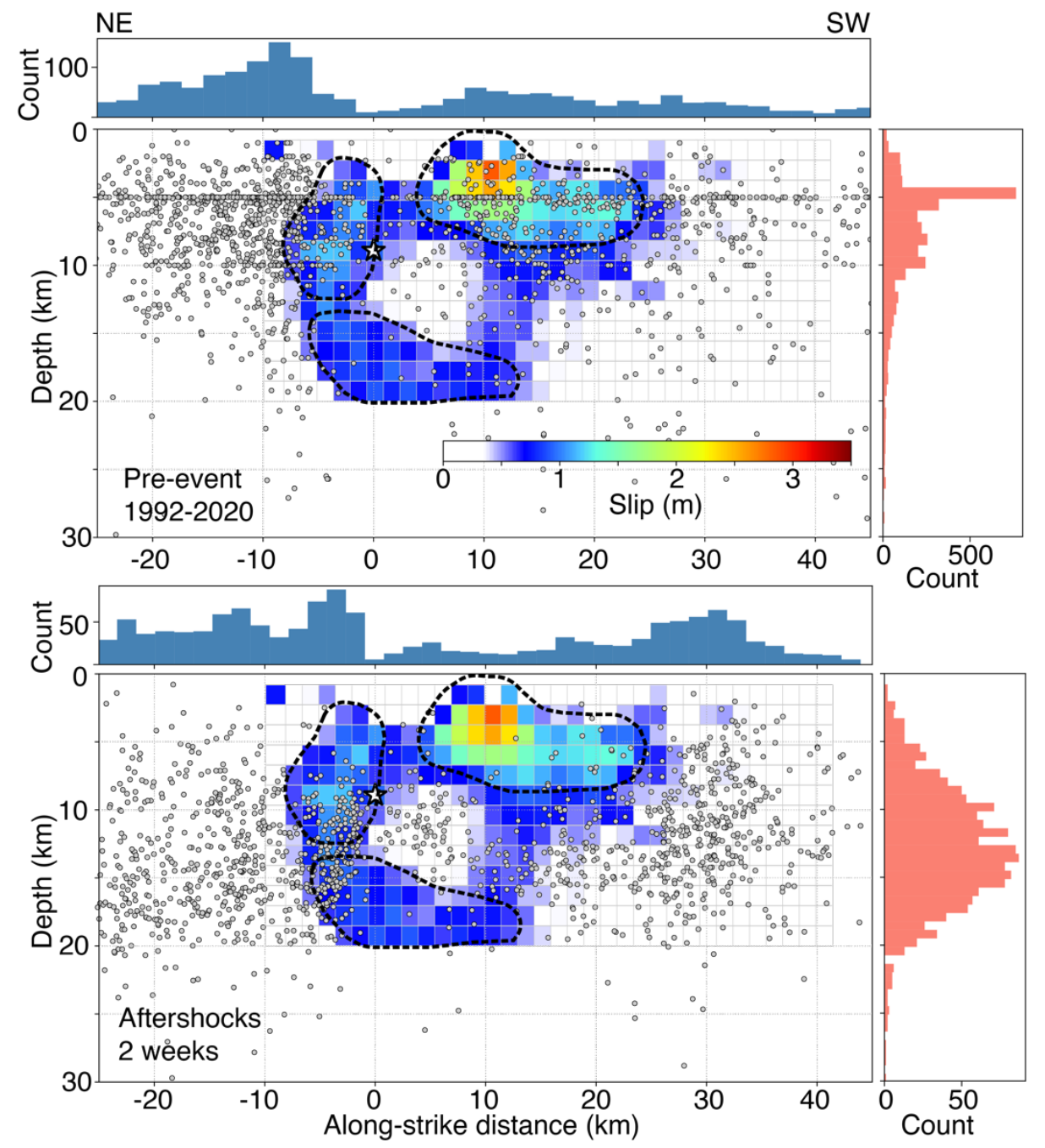

Fig. 10. (Top panel) Pre-event seismicity within $20 \mathrm{~km}$ of the fault trace from the KOERI catalogue dating back to 1992. (Bottom panel) Relocated hypocenters of the first 2 weeks of aftershock activity. Down-dip and along-strike histograms with the number of events are shown. The streak of events at $5 \mathrm{~km}$ depth in the pre-event catalogue is an artefact. KOERI events default to $5 \mathrm{~km}$ depth and remain there unless the location is revised by an analyst at a later date. The KOERI location of the mainshock's hypocentre, that was used for the slip modeling, is displayed by a star.

\subsection{Implications for the EAF}

It is obvious that the 24 January $2020 M w 6.7$ Doğanyol-Sivrice earthquake filled, at least partially, the existing seismic gap along the Sivrice-Doğanyol-Pütürge segment (Fig. 1) as clear surface 
ruptures produced by large earthquakes during the $19^{\text {th }}-20^{\text {th }}$ centuries in the East Anatolian Fault have been reported and mapped by many studies (e.g.: Ambraseys 1989; Ambraseys, and Jackson 1998; Duman and Emre, 2013 and references therein). Slip partitioning occurs along many segments of the East Anatolian Fault Zone (see Fig. 1 fault segments nos: 1-11) that is linked to nearby major plate-boundary fault systems, specifically the Dead Sea Fault (DSF), the Cyprus Arc (CA), and Misis Fault (MF) in the eastern Mediterranean region. Recently, Bletery et al. (2020) calculated a coupling map from InSAR and GNSS long-term velocities which suggests regions with slip deficit between 50-80\% along the ruptured fault segment. However, they observe much smaller accumulated seismic moment within the rupture region of the $M w 6.7$ Doğanyol-Sivrice earthquake since the 1905 failure (Ms 6.7) (e.g. Taymaz et al., 1991). As a result, they concluded that the recent earthquake likely did not rupture the same portion of the fault segment as the 1905 earthquake. They reported relatively high and deep variation of slip deficit along the NAFZ. Meanwhile, possible locking on the EAFZ is high, but much shallower, being restricted to the first $5 \mathrm{~km}$. There is an apparent disagreement between regions of predicted slip deficit at shallow depths along the EAFZ (Bletery et al., 2020) and three high resolution slip-patches imaged between 3 and $20 \mathrm{~km}$, following our joint modelling of space geodetic data. This is possibly caused by depth resolution issues between the data sets (e.g. ENVISAT satellite InSAR data and GNSS historic velocities for the inter-seismic locking vs. co-seismic SENTINEL-1 satellite InSAR and high-rate GNSS for the rupture modeling).

On the other hand, insufficient data has not yet allowed for the calculation of recurrence intervals of the major earthquakes in the EAFZ though some clear fault segments and restraining stepovers are still capable of producing large earthquakes in the region. We cannot conclude yet whether there is a substantial contribution from aseismic deformation processes as observed at other tectonically active zones. Furthermore, earthquakes with a strong or moderate moment magnitude $(M w>6.0)$ transfer stresses upon other faults which are located near to the mainshock, (Stein, 1999) thus changing recurrence intervals by modifying times to failure (advancing or delaying).

The geologists of MTA (2020) also did not observe any major surface ruptures from this earthquake, as similarly reported for the past earthquakes of 2003 Bingöl $M w 6.0$ and 2010 Kovancilar-Elazığ $M w 6.1$ (no major surface ruptures were documented). This is consistent with reduced shallow slip in the inversion (Fig. 6), where it seems clear that the $M w 6.7$ rupture stopped just short of the surface, perhaps at about 2-3 km depth. This is further buttressed by the presence of a gradient of phase across the fault as shown in the InSAR profiles, rather than a sharp discontinuity, as presented in Fig. 2.

\section{Conclusions}

We have presented the results of a kinematic slip model for the $2020 \mathrm{Mw} 6.7$ Doğanyol-Sivrice, Turkey Earthquake, on the East Anatolian Fault Zone. Our slip model is constrained by two Sentinel-1 interferograms and by 5 three-component high-rate GNSS recordings close to the earthquake source. We find that most of the slip occurs predominantly in three regions; two of them at between 2 and $10 \mathrm{~km}$ depth and a deeper slip region extending down to $20 \mathrm{~km}$ depth. We also relocated the first two weeks of aftershocks and find a distribution of events that agrees with these gross features. We have shown that the HR-GNSS recordings suggest a strongly unilateral rupture with the effects of a directivity pulse clearly seen in the waveforms and in the MMIs measured by the GNSS velocities. The slip model supports rupture propagation from northeast to 
southwest at a relatively slow speed of $2.2 \mathrm{~km} / \mathrm{s}$ and a total source duration of $\sim 20 \mathrm{~s}$ on a $35 \times 20 \mathrm{~km}^{2}$ fault. The Doganyol-Sivrice earthquake is the most important event in the last 50 years on the East Anatolian Fault zone. Without availability of regional seismic data, space geodetic observations provide the best opportunity to model and understand the slip distribution and its temporal evolution.

\section{Acknowledgements}

We would like to thank Istanbul Technical University Research Fund, the National Scientific and Technological Research Council of Turkey (TUBITAK), Turkish Academy of Sciences (TUBA) in the framework for Young Scientist Award Program (TUBA-GEBIP), The Science Academy Chamber-Turkey (BAGEP), and the Alexander von Humboldt Foundation Research Fellowship Award for financial support and for further providing computing facilities and other relevant computational resources through Humboldt-Stiftung Follow-Up Programme.

We gratefully acknowledge permission to use GNSS data from the Turkish National Permanent GNSS/RTK Network (TUSAGA-Aktif/CORS-TR administrated by General Directorate of Land Registry and Cadastre-TKGM and General Directorate of Mapping-HGM, Ankara, Turkey). We appreciate the Disaster and Emergency Management Presidency of Turkey (AFAD) providing initial catalogue of aftershocks and phase-arrival data acquired from their bulletin resources for the period 24 January 2020 - 11 February 2020. We appreciate BU-KOERI for delivering the earthquake catalogue of Turkey to present background seismicity between 1992 and 2020. We are further grateful to our graduate students Ceyhun Erman and Derya Keleş for helping us to combine phase data of AFAD-DAD aftershocks catalogue for relocation procedures and helping us to accumulate documented historical earthquakes. We thank ESA, Geohazards Lab and Terradue for providing access to Geohazards Exploitation Platform (GEP) for InSAR cloud processing

Athanassios Ganas and Vassilis Kapetanidis thank "HELPOS - Hellenic Plate Observing System" (MIS 5002697) which is funded by the Operational Programme "Competitiveness, Entrepreneurship and Innovation" (NSRF 2014-2020) and co-financed by Greece and the European Union (European Regional Development Fund).

We have further benefited fruitful discussions with Ömer Emre, Stathis C. Stiros, and Tuna Eken for interpretation of neotectonic features observed, and Oguz C. Celik for structural damages reported in the catastrophic area. We thank Quentin Bletery and Jean-Mathieu Nocquet for sending us the preprint of their unpublished paper on coupling at the EAF that is still under review.

\section{References}

AFAD., 2020. Report on 24 January 2020 Sivrice (Elazığ) Mw 6.8 Earthquake, Disaster and Emergency Management Presidency of Turkey, Ministry of Interior, Ankara, Turkey, 46 pages (https://deprem.afad.gov.tr; last accessed on 29 February 2020).

Allen, C. R. 1969. Active faulting in northern Turkey. Rep. 1577, 32 pp., Div. of Geol. Sic., Calif. Inst. of Technol., Pasadena.

Allen, T. I., \& Hayes, G. P. (2017). Alternative rupture-scaling relationships for subduction interface and other offshore environments. Bulletin of the Seismological Society of America, 107(3), 1240-1253. 
Ambraseys, N.N., 1989. Temporary seismic quiescence: SE Turkey, Geophys. J. Int., 96, 311-331. Ambraseys, N.N., Jackson, J.A., 1998. Faulting associated with historical and recent earthquakes in the Eastern Mediterranean region. Geophys. J. Int. 133, 390-406, doi:10.1046/j.1365246X.1998.00508.x.

Bletery, Q., Cavalie, O., Nocquet, J-M., Ragon, T., 2020. Distribution of interseismic coupling along the North and East Anatolian Faults inferred from InSAR and GPS data. Geophys. Res. Lett. (submitted on March 5, 2020), Earth and Space Science Open Archive, https://www.essoar.org/doi/10.1002/essoar.10502450.1

Chen, C.W., Zebker, H.A., 2002. Phase unwrapping for large SAR interferograms: Statistical segmentation and generalized network models. IEEE Transactions on Geoscience and Remote Sensing 40, 1709-1719.

Colosimo, G., Crespi, M., Mazzoni, A., 2011. Real-time GPS seismology with a stand-alone receiver: A preliminary feasibility demonstration. J. Geophys. Res., 116 (B11).

Confal, J., Faccenda, M., Eken, T., Taymaz, T., 2018. Numerical Simulation of 3-D Mantle Flow Evolution in Subduction Zone Environments in Relation to Seismic Anisotropy Beneath the Eastern Mediterranean Region, Earth and Planetary Science Letters (EPSL), Vol. 497, 50-61. https://doi.org/10.1016/j.epsl.2018.06.005.

Delph, J.R., Biryol, C.B., Beck, S.L., Zandt, G. Ward, K.M., 2015. Shear wave velocity structure of the Anatolian Plate: anomalously slow crust in southwestern Turkey. Geophys. J. Int., 202, 261-276, doi:10.1093/gji/ggv141.

Duman, T.Y., Emre, Ö., 2013. The East Anatolian Fault: geometry, segmentation and jog characteristics. Geological Society, London, Special Publications 372, 495-529, https://doi.org/10.1144/SP372.14.

Farr, T. G., et al. 2007. The Shuttle Radar Topography Mission. Rev. Geophys. 45, RG2004, doi:10.1029/2005RG000183.

Feng, W., Lindsey, E., Barbot, S., Samsonov, S., Dai, K., Li, P., Li, Z., Almeida, R., Chen, J., Xu, X. 2016. Source characteristics of the $2015 \mathrm{Mw} 7.8$ Gorkha (Nepal) earthquake and its Mw 7.2 aftershock from space geodesy, Tectonophysics, doi:10.1016/j.tecto.2016.02.029

Fichtner, A., Saygin, E., Taymaz, T., Cupillard, P., Capdevillee, Y., Trampert, J. 2013. The Deep Structure of the North Anatolian Fault Zone, Earth and Planetary Science Letters, July 2013, Vol: 373, pp. 109-117, doi:10.1016/j.eps1.2013.04.027.

Fielding, E.J., Lundgren, P.R., Taymaz,T., Yolsal-Çevikbilen, S. and Owen, S.E. (2013). FaultSlip Source Models for the 2011 M7.1 Van Earthquake in Turkey from SAR Interferometry, Pixel Offset Tracking, GPS and Seismic Waveform Analysis, Seismological Research Letters, Vol: 84 (4), 579-593, SRL-D-12-00164, https://doi.org/10.1785/0220120164.

Galetzka, J., Melgar, D., Genrich, J.F., Geng, J., Owen, S., Lindsey, E.O., Xu, X., Bock, Y., Avouac, J.P., Adhikari, L.B., Upreti, B.N., 2015. Slip pulse and resonance of the Kathmandu basin during the 2015 Gorkha earthquake, Nepal. Science 349(6252), 1091-1095.

Ganas, A, Kourkouli, P, Briole, P, Moshou, A, Elias, P, Parcharidis, I, 2018. Coseismic Displacements from Moderate-Size Earthquakes Mapped by Sentinel-1 Differential Interferometry: The Case of February 2017 Gülpinar Earthquake Sequence (Biga Peninsula, Turkey). Remote Sens. 10, 1089, http://www.mdpi.com/2072-4292/10/7/1089.

Ganas, A., Elias, P., Kapetanidis, V., Valkaniotis, S., Briole, P., Kassaras, I., Argyrakis, P., Barberopoulou, A., Moshou, A., 2019. The July 20, 2017 M6.6 Kos Earthquake: Seismic and Geodetic Evidence for an Active North-Dipping Normal Fault at the Western End of the Gulf of Gökova (SE Aegean Sea). Pure and Applied Geophysics 176 (10), 4177-4211 https://doi.org/10.1007/s00024-019-02154-y. 
Goldstein, R. M., Werner, C. L. 1998. Radar interferogram filtering for geophysical applications. Geophys. Res. Lett., 25(21), 4035-4038.

Grapenthin, R., West, M., Freymueller, J., 2017. The utility of GNSS for earthquake early warning in regions with sparse seismic networks. Bulletin of the Seismological Society of America 107(4), 1883-1890.

Herring, T.A., King, R.W. McClusky, S.C., 2010. Introduction to Gamit/Globk. Massachusetts Institute of Technology, Cambridge, Massachusetts.

Ilieva, M., P. Briole, A. Ganas, D. Dimitrov, P. Elias, A. Mouratidis, R. Charara, 2016. Fault plane modelling of the 2003 August 14 Lefkada Island (Greece) earthquake based on the analysis of ENVISAT SAR interferograms. Tectonophysics 693, 47-65, ISSN 0040-1951, http://dx.doi.org/10.1016/j.tecto.2016.10.021

Kim, A., Dreger, D.S., 2008. Rupture process of the 2004 Parkfield earthquake from near fault seismic waveform and geodetic records. J. Geophys. Res., 113(B7).

Kind, R., Eken, T., Tilmann, F., Sodoudi, F., Taymaz, T., Bulut, F., Yuan, X., Can, B., Schneider, F., 2015. Thickness of the Lithosphere Beneath Turkey and Surroundings from S-Receiver Functions, Solid Earth, 6, 971-984, 2015, www.solid-earth.net/6/971/2015, doi:10.5194/se-6971-2015.

Kissling, E., Ellsworth, W.L., Eberhart-Phillips, D., Kradolfer, U., 1994. Initial reference models in local earthquake tomography. J. Geophys. Res., doi:10.1029/93JB03138

Klein, F.W., 2002. User's guide to HYPOINVERSE-2000: a Fortran program to solve for earthquake locations and magnitudes. U.S. Geol. Surv. Prof. Pap., rep. 02-17, 1-123

Lohman, R.B., Simons, M., 2005. Some thoughts on the use of InSAR data to constrain models of surface deformation: Noise structure and data down-sampling. Geochemistry, Geophysics, Geosystems 6(1).

Melgar, D., Crowell, B.W., Bock, Y., Haase, J.S., 2013. Rapid modeling of the 2011 Mw 9.0 Tohoku-Oki earthquake with seismogeodesy. Geophysical Research Letters 40(12), 29632968.

Melgar, D., Bock, Y., 2015. Kinematic earthquake source inversion and tsunami runup prediction with regional geophysical data. J. Geophys. Res., 120(5), 3324-3349.

Melgar, D., Fan, W., Riquelme, S., Geng, J., Liang, C., Fuentes, M., Vargas, G., Allen, R.M., Shearer, P.M., Fielding, E.J., 2016. Slip segmentation and slow rupture to the trench during the 2015, Mw8. 3 Illapel, Chile earthquake. Geophysical Research Letters 43(3), 961-966.

Melgar, D. and Hayes, G.P., 2017. Systematic observations of the slip pulse properties of large earthquake ruptures. Geophysical Research Letters, 44(19), pp.9691-9698.

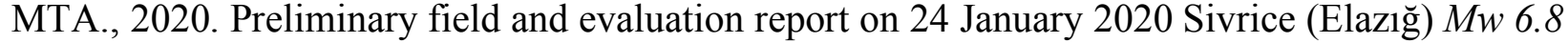
Earthquake, General Directorate of Mineral Research and Explorations of Turkey (MTA), Ministry of Energy and Natural Resources, Ankara, 48 pages (https:// https://www.mta.gov.tr/; last accessed on 27 February 2020).

Nabelek, J.L., 1984. Determination of earthquake source parameters from inversion of body waves, Ph.D. Thesis, MIT, Cambridge, MA, USA.

Pasyanos, M.E., Masters, T.G., Laske G., Ma, Z., 2014. LITHO1.0: An updated crust and lithospheric model of the Earth. J. Geophys. Res., 119 (3), 2153-2173, doi: 10.1002/2013JB010626.

Reilinger, R. et al., 2006. GPS constraints on continental deformation in the Africa-ArabiaEurasia continental collision zone and implications for the dynamics of plate interactions. J. Geophys. Res., 111, B05411, doi:10.1029/2005JB004051. 
Somerville, P.G., 2003. Magnitude scaling of the near fault rupture directivity pulse. Physics of the earth and planetary interiors, 137(1-4), pp.201-212.

Shu, Y., Fang, R., Li, M., Shi, C., Li, M., Liu, J., 2018. Very high-rate GPS for measuring dynamic seismic displacements without aliasing: performance evaluation of the variometric approach. GPS Solutions, 22(4), 121.

Stein, R. S.,1999. The role of stress transfer in earthquake occurrence. Nature, 402, 605-609.

Tan, O., Taymaz, T., 2006. Active Tectonics of the Caucasus: Earthquake Source Mechanisms and Rupture Histories Obtained from Inversion of Teleseismic Body-Waveforms. In: PostCollisional Tectonics and Magmatism in the Mediterranean Region and Asia, Geological Society of America, Special Paper 409, pp: 531-578, doi:10.1130/2006.2409 (25).

Taymaz, T., Eyidoğan, H., Jackson, J., 1991. Source parameters of large earthquakes in the East Anatolian fault Zone (Turkey). Geophys. J. Int., 106, 537-550, doi:10.1111/j.1365246X.1991.tb06328.x.

Taymaz, T., Westaway, R., Reilinger, R., 2004. Active Faulting and Crustal Deformation in the Eastern Mediterranean Region, Special Issue of Tectonophysics, Vol: 391, Issues 1-4, 375 pages, October 29, 2004. doi:10.1016/j.tecto.2004.07.005.

Taymaz, T., Yilmaz, Y., Dilek, Y., 2007a. The Geodynamics of the Aegean and Anatolia: Introduction. In: The Geodynamics of the Aegean and Anatolia (eds. Tuncay Taymaz, Yücel Y1lmaz \& Y1ldırım Dilek), pp. 1-16, The Geological Society of London, Special Publications Book, Vol: 291, ISBN: 978-1-86239-239-7.

Taymaz, T., Wright, T., Yolsal, S., Tan, O., Fielding, E., Seyitoğlu, G., 2007b. Source Characteristics of June 6, 2000 Orta-Çankırı (Central Turkey) Earthquake: a synthesis of seismological, geological and geodetic (InSAR) observations, and internal deformation of Anatolian plate. In: The Geodynamics of the Aegean and Anatolia (eds. Tuncay Taymaz, Yücel Yllmaz \& Yıldırım Dilek), pp. 259-290, The Geological Society of London, Special Publications Book, Vol: 291, ISBN: 978-1-86239-239-7.

Trifonov, V.G., Çelik, H., Simakova, A.N., Bachmanov, D.M., Frolov, P.D., Trikhunkov, Y.I., Tesakov, A.S., Titov, V.M., Lebedev, V.A., Ozherelyev, D.V., Latyshev, A.V., Sychevskaya, E.K., 2018. Pliocene - Early Pleistocene history of the Euphrates valley applied to Late Cenozoic environment of the northern Arabian Plate and its surrounding, eastern Turkey. Quaternary International 493, 137-165, https://doi.org/10.1016/j.quaint.2018.06.009

Vanacore, E.A, Taymaz T., Saygin, E., 2013. Moho Structure of the Anatolian Plate from Receiver Function Analysis,_Geophys. J. Int.,_193 (1), 329-337, https://doi.org/10.1093/gji/ggs107.

Veci, L., Lu, J., Prats-Iraola, P., Scheiber, R., Collard, F., Fomferra, N., Engdahl, M., 2014. The Sentinel-1 toolbox. In Proceedings of the IEEE International Geoscience and Remote Sensing Symposium (IGARSS) (pp. 1-3). IEEE.

Waldhauser, F., 2001. hypoDD-A Program to Compute Double-Difference Hypocenter Locations. U.S. Geol. Surv. Open File Rep. 01-113, 25 p.

Worden, C.B., Gerstenberger, M.C., Rhoades, D.A., Wald, D.J., 2012. Probabilistic relationships between ground-motion parameters and modified Mercalli intensity in California. Bulletin of the Seismological Society of America 102(1), 204-221.

Zhu, L., Rivera, L.A., 2002. A note on the dynamic and static displacements from a point source in multilayered media. Geophys. J. Int. 148(3), 619-627. 